\title{
Preceptoras estrangeiras para educar meninas nas casas brasileiras do século XIX
}

Foreign preceptors to educate girls in Brazilian houses of the 19th century

Preceptoras extranjeras para educar a las niñas en las casas brasileñas del siglo XIX

\author{
MARIa CEli Chaves VASCONCELOS ${ }^{1}$
}

\section{Resumo}

No Brasil, o século XIX foi o período em que muitas mulheres europeias, principalmente alemãs, francesas e inglesas, aportaram no país, para exercerem o ofício de preceptoras nas casas da Corte Imperial, anunciando seus préstimos pelos jornais de grande circulação na época. O estudo tem como objetivo demonstrar a incidência da chegada dessas mulheres, nos anos de 1880, para o trabalho como preceptoras nas casas das elites oitocentistas, bem como discutir as práticas de educação que desenvolviam para ensinar, notadamente, meninas. Tratase de uma pesquisa histórico-documental, cujas fontes incluem anúncios e matérias de jornais e revistas de educação e de instrução destinadas às famílias e às mulheres, além de literatura e egodocumentos, como diários e cartas, escritos pelas próprias preceptoras ou por testemunhos dessa prática. Conclui-se que a educação, a cargo de preceptoras europeias, era considerada uma distinção social e continha práticas de educação análogas aos modelos escolares europeus.

Palavras-chave: Educação doméstica de meninas. Preceptoras. Brasil oitocentista.

\footnotetext{
${ }^{1}$ Doutora em Educação pela Pontifícia Universidade Católica do Rio de Janeiro. Professora Associada da Universidade do Estado do Rio de Janeiro, atuando no Programa de Pós-Graduação em Educação. Bolsista de Produtividade do CNPq. Procientista/Uerj e Cientista do Nosso Estado/Faperj. E-mail: maria2.celi@gmail.com
} 


\begin{abstract}
In Brazil, the nineteenth century was the period in which many European women, mainly German, French and English, came to country to perform the office of preceptors in the houses of the Imperial Court, announcing their services by newspapers of great circulation at the time. The study aims to demonstrate the incidence of the arrival of these women, in the $1880 \mathrm{~s}$, for the work of preceptors in the houses of nineteenth-century elites, as well as discuss the educational practices they developed to teach, especially girls. This is a historicaldocumentary research whose sources include advertisements and articles from newspapers and magazines of education and instruction for families and women, as well literary texts as egodocuments, such as diaries and letters written by the preceptors themselves or by witnesses of this practice. It was concluded that education, by European preceptors, was considered a social differential and contained educational practices analogous to European school models.
\end{abstract}

Keywords: Domestic girls' education. Preceptors. Nineteenth-century Brazil.

\title{
Resumen
}

En Brasil, el siglo XIX fue el período en que muchas mujeres europeas, principalmente, alemanas, francesas y inglesas, aportaron en país para ejercer el oficio de preceptoras en las casas de la Corte Imperial, anunciando sus servicios por los diarios de gran circulación en la época. El estudio tiene como objetivo demostrar la incidencia de la llegada de esas mujeres, en los años 1880, al trabajo de preceptoras en las casas de las élites del ochocientos, así como discutir las prácticas de educación que desarrollaban para enseñar, en particular, a las niñas. Se trata de una investigación histórico-documental, cuyas fuentes incluyen anuncios y materias de periódicos y revistas de educación e instrucción destinadas a las familias y las mujeres, además de literatura y egodocumentos, como diarios y cartas, escritos por las propias preceptoras o por testigos de esa práctica. Se concluye que la educación, a cargo de preceptoras europeas, se consideraba un diferencial social y contenía prácticas de educación análogas a los modelos escolares europeos.

Palabras clave: Educación doméstica de las niñas. Preceptoras. Brasil del ochocientos. 


\section{Uma cidade e suas visitantes: mulheres estrangeiras no Rio de Janeiro oitocentista}

Nas últimas décadas do século XIX, por entre as estreitas ruas da Freguesia da Candelária, também conhecida como "cidade velha", e seus arredores, as Freguesias de Santana, Santa Rita, Sacramento, Santo Antônio e São José, estendiam-se inúmeras moradias que compunham a zona urbana da cidade, o Rio de Janeiro, capital do Império do Brasil ${ }^{2}$, cuja população local e de estrangeiros que nela chegavam - para trabalhar, montar comércio, vender serviços - aumentava a cada dia (SENNA, 2006; BARROS, 2007; GERSON, 2013).

De acordo com Oliveira (2011, p. 159), “[...] a cidade transformava-se com certa rapidez. Em 1872, por exemplo, o Rio de Janeiro contava com uma população em torno de 274.972 habitantes, sendo que 84.288 eram estrangeiros". Era uma cidade "culturalmente heterogênea" (Ibidem), onde diferentes visões de mundo conviviam em um cenário peculiar, sob diversos aspectos; entre eles, a paisagem, o clima, e a escravidão exposta por todos os lados. E também tinha lá seu glamour: nela se localizava a Corte Imperial; e as notícias enviadas à Europa enalteciam a possibilidade de fazer "fortuna", a prosperidade do comércio de produtos importados, a abundância de pedras preciosas, as terras férteis, as plantas exóticas e a vida opulenta e cercada de escravos que levavam os ricos fazendeiros, atraindo e mexendo com a imaginação de inúmeros destemidos viajantes, seja para locupletar-se das riquezas contadas, seja para livrar-se das adversidades vividas em seus países de origem (LEITE, 1984; FRANÇA, 1999, 2008, 2013; PAIVA, 2011).

Entre os viajantes que buscavam poder recomeçar a vida em algum ponto desconhecido, mas cujo anonimato causado pela distância não fosse tão severo a ponto de privá-los de uma existência material próxima daquela a que estavam acostumados, encontravam-se muitas mulheres, vindas de distintos países, cujo destaque de sua participação neste conjunto era o fato de terem empreendido essa viagem "solteiras" ou sem a companhia e a proteção de um "marido", que as escoltasse desde o embarque nos portos da Europa, percorrendo os longos dias cruzando o oceano a bordo de um vapor, até a chegada aos portos brasileiros; neste caso, no Rio de Janeiro, e sua imediata acomodação na cidade (BINZER, 1994; COSTA, 2010; CAMURÇA, 2012).

Essa condição de mulheres desacompanhadas de um cônjuge, que tinham, entre seus propósitos de viagem, o de conseguir um trabalho no Brasil, difere, fundamentalmente, de muitas outras viajantes estrangeiras, como Jemima Kindersley, Elizabeth Macquarie e Rose Freycinet, que, como narra França (2008), vieram ao país junto com seus maridos, todos em missão militar. Nessa posição, apesar de compactuarem com aquilo que Del Priore (2008, p. 7) descreve como "perigos, dificuldades materiais", e "armadilhas de toda a sorte" que as "espreitavam", contavam com seus companheiros e, nestes casos, com uma esquadra, para defendê-las, situação muito diversa daquela vivida por quem embarcava rumo ao "novo mundo" na condição de mulher solteira, embora sujeitas aos mesmos sentimentos a que Del Priore se refere:

\footnotetext{
2 Município Neutro era a designação da cidade do Rio de Janeiro, instituída pelo Ato Adicional à Constituição de 1824, em 12 de agosto de 1834, até a proclamação da República no Brasil, em 15 de novembro de 1889; embora a nomenclatura somente tenha mudado com a promulgação da Constituição de 1891, quando a cidade passou a ter a denominação de Distrito Federal.
} 
As dificuldades da viagem eram contrabalançadas, contudo, pelo que alguém denominou de "o nobre desejo de correr o mundo". Viajar não era só se deslocar no espaço. Era melhor observar e conhecer terras nunca dantes percorridas. E fazê-lo com serenidade e atenção. Se, em épocas remotas, partia-se apenas para fugir dos inimigos ou da guerra, ao longo do tempo e da história as viagens se transformaram no caminho mais curto entre um indivíduo e outro (DEL PRIORE, 2008, p. 7).

De acordo com Paiva (2011, p. 121), chegando ao Brasil, o olhar dos forasteiros era "imbuído de estereótipos" e preconceitos, mas ao mesmo tempo tornava-se "[...] desbravador, inquieto, atento às diferenças, comparativo por excelência”. Assim, produziram preciosos registros daquilo que encontraram e viram, desde o desembarque. A entrada da Baía de Guanabara, por si só, proporcionava uma visão inesquecível, como registra o inglês Oswald Brierly, em sua terceira viagem ao Brasil, ocorrida em 1867, período próximo ao do enfoque deste estudo: "O dia estava muito lindo e as terras altas ao redor do Rio, elevando-se acima da névoa, estavam particularmente grandiosas" (BRIERLY, 2006, p. 124). À frente, a cidade.

A cidade, por sua vez, nos anos de 1870 e 1880, décadas em que se localiza no Rio de Janeiro um grande número de mulheres estrangeiras "recém-chegadas da Europa", oferecendo seus serviços pelos jornais de grande circulação, tinha muitas peculiaridades, as quais, os estrangeiros, assim que desembarcavam, precisavam decifrar; entre elas, inicialmente, os transportes e as acomodações urbanas. Chegar ao Rio de Janeiro no último quartel do século XIX, significava deparar-se com os bondes de tração animal que, por sinal, revolucionavam "os costumes da população" (RENAULT, 1982), mas também conviver com as antigas vitórias, caleças, tilburis, faetons, que faziam o transporte individual (MOURA, 1988; EDMUNDO, 2007; 2009).

Quanto às acomodações para a permanência na cidade, poder-se-ia alugar uma casa, "bons cômodos" ou optar por um hotel, o que faziam, provavelmente, as mulheres estrangeiras em busca de emprego até que sua colocação estivesse arranjada. De acordo com Renault (1982), no início do ano de 1870, o cenário apresentado pelos anúncios dos jornais da Corte carioca em relação à hotelaria era esse:

O francês explora o comércio de hotelaria. Dos mais famosos é o Hotel das Quatro Nações, de Charles Luc, que oferece "diners et soupers trés bien servis à l'heure". O Hotel de Londres, na rua do Ouvidor, dispõe de cozinheiro francês, "mesa redonda às 9 horas e 4 da tarde"3. O pensionista paga $30 \$ 4$ ao mês. O Hotel de Milão, o Ravot, o Hotel da Europa estão entre os mais conhecidos (RENAULT, 1982, p. 21) ${ }^{5}$.

\footnotetext{
${ }^{3}$ Uma espécie de Buffet com preço fixo (RENAULT, 1982, p. 21).

${ }^{4}$ É lido como trinta réis. Para se ter ideia do valor, uma "boa" casa, em 1869, era alugada "em bairro nobre por 40\$” (RENAULT, 1982, p. 20).

${ }^{5}$ A ortografia de todas as citações copiadas dos originais oitocentistas foi adequada aos padrões modernos de escrita para facilitar o entendimento do texto.
} 
Para um estrangeiro versado em francês, não era muito difícil comer e dormir na cidade, pois, no comércio, os produtos conservavam o nome original nessa língua. Aliás, a cidade tinha características da imitação francesa por toda a parte: na língua, na moda, no que era considerado belas-artes, na música, nos penteados (PINHO, 2004; CHATAIGNIER, 2010; OLIVEIRA, 2011). Ina von Binzer, uma alemã e perfeita representante das jovens mulheres estrangeiras que vieram ensinar no Brasil, nos anos de 1880, demonstra essa influência e predileção pela França em suas memórias de preceptora: “[...] parece que não existem quase brasileiros que não falem francês, embora alguns deles possuam apenas uma vaga noção sobre o país a que essa língua pertence, ignorando mesmo que existem mais algumas cidadezinhas além de Paris" (BINZER, 1994, p. 18).

Uma vez instaladas no Rio de Janeiro, a primeira opção para a residência, no país, das mulheres que, praticamente sozinhas ou desacompanhadas de qualquer parente, já tinham passado por uma epopeia cruzando o oceano, era enfrentar a busca por um emprego que pudesse sustentá-las e até garantir a moradia. Nesse tempo e contexto do Rio de Janeiro oitocentista, nas suas últimas décadas, um dos poucos ofícios aceitos e apreciados para mulheres era ensinar; além do mais, tornava-se também o único possível para as que não possuíam nenhum outro talento, mas haviam frequentado colégios europeus. Assim, poderiam, tão-somente, educar outras crianças, reproduzindo aquilo que aprenderam. Também eram detentoras do diferencial de saber perfeitamente a língua francesa, por serem daquele país, ou porque o francês também era a língua dominante na Europa, sendo essa a primazia sobre os conhecimentos femininos a serem buscados pelas famílias (SOUSA, 1987; VASCONCELOS, 2005; 2011; 2013; MALTA, 2011; VERONA, 2013).

A fim de demonstrar a incidência da chegada dessas mulheres europeias para ensinar crianças e jovens, notadamente meninas, nas casas das elites oitocentistas, o presente artigo faz uma incursão pelos anúncios colocados nos periódicos de grande circulação na Corte, o Rio de Janeiro, particularmente os que foram publicados no Jornal do Commercio, no ano de 1880. Essa delimitação foi escolhida, a priori, por se tratar do início de uma década decisiva para o País e, na qual, as mudanças sociais e políticas do devir já eram prenunciadas pelos jornais. A pesquisa também revelou que os anos de 1880 são aqueles em que há a maior frequência de anúncios relativos à oferta e demanda dos serviços de educação doméstica, ao longo do século XIX, proporcionando vestígios mais amplos para o estudo dessa prática, na qual designamos como preceptoras, mulheres professoras, também chamadas de "governantas", e que residiam na casa de seus alunos; e como professoras particulares aquelas que somente "dão lição por casa", com dia e hora estabelecidos semanalmente (FERNANDES, 1994; VASCONCELOS, 2005; ALBUQUERQUE, 2005; 2015).

A par da colocação das mestras nas categorias indicadas, o estudo propõe-se, ainda, evidenciar possíveis conteúdos e práticas de educação que essas mulheres estrangeiras desenvolviam para ensinar, sobretudo, meninas, nas casas das famílias que as contratavam. Cabe destacar que a educação oferecida e consentida pelos senhores para ser ministrada às suas filhas, no ambiente doméstico, era considerada equivalente à escolarização adquirida em instituições de ensino, já existentes, como escolas, colégios, liceus, recolhimentos etc. Assim, não se tratava de uma educação "informal", mas de uma modalidade de educação 
reconhecida, até mesmo na legislação e nos documentos oficiais que se referiam à obrigatoriedade do ensino, excetuando dessa obrigação os pais que mandavam educar filhos, filhas e crianças sob sua responsabilidade na casa ${ }^{6}$.

$\mathrm{O}$ artigo provém de uma pesquisa histórico-documental, cujas fontes incluem anúncios do Jornal do Commercio e matérias de revistas de educação e de instrução, destinadas às famílias e às mulheres, além de lacunas preenchidas pela literatura e por egodocumentos, como diários e cartas, escritos pelas próprias preceptoras ou por testemunhos dessa prática de educação doméstica, bastante apreciada no Brasil oitocentista, por ser vista como um diferencial social e que continha modelos de ensino análogos aos modelos escolares europeus. A opção pelo foco central nos anúncios reveste-se daquilo que Gilberto Freyre (2010, p. 88) afirma: “[...] mais do que nos livros de história e nos romances, a história do Brasil do século XIX está nos anúncios dos jornais".

$\mathrm{O}$ artigo está dividido em dois tópicos principais. O primeiro demonstra a chegada das mulheres estrangeiras na Corte e sua contratação pelas famílias, sendo esse um hábito permanente durante todo o século XIX, que amplia sua oferta e demanda nos anos de 1880. A seguir, enfoca-se o padrão de educação feminina, possivelmente utilizado por essas mulheres estrangeiras para ensinar nas casas brasileiras, por meio dos manuais de educação doméstica publicados no país e copiados do exterior.

\section{"Entre nós já se vai introduzindo o costume": preceptoras anunciadas pelo Jornal}

Com essa frase, o periódico O Album Semanal, Chronologico, Litterario, Critico e de Moda ${ }^{7}$, publicado num domingo, em 21 de dezembro 1851, constatava a influência estrangeira no país, que ia introduzindo um novo costume, o das pessoas apresentarem-se umas as outras, especialmente as mulheres, pois isso evitaria que ficassem sentadas olhandose mutuamente em silêncio.

Porém não se deve fazer isto muito oficialmente, nem com gravidade inglesa; mas com a graça que a senhora bem educada tem em todas as suas maneiras. Assim, por exemplo: duas senhoras, que não se conhecem, estão assentadas uma ao pé da outra: a dona da casa, colocando-se diante delas, pegaria na mão da mais moça, e dirá à mais velha: Tenho o prazer de apresentar-vos a Sra. D. F., cujo marido, ou cujo filho, ou cujo pai (aqui deverá procurar alguma qualidade boa para dizer de qualquer destes senhores.). Depois voltar-se-á para a mais velha, e dir-lhe-á: Estimo muito que a senhora ficasse ao pé da Sra. D. F.. [...] depois retirar-se-á; e então essas duas senhoras conversarão, e não ficarão como até aí a olhar-se mutuamente em silêncio (VARIEDADES, 1851, p. 1).

\footnotetext{
${ }^{6}$ Com base em pesquisas realizadas anteriormente pela autora (VASCONCELOS, 2005, 2008, 2011, 2013), a denominação utilizada de "educação na casa" refere-se à sua equiparação/inversão à "educação na escola", cuja subjetividade é diferente da abrangida por "educação em casa", ou seja, essa prática/modalidade é exposta como educação formal realizada na própria casa do aluno.

${ }^{7}$ O periódico intitulado O Album Semanal, Chronologico, Litterario, Critico e de Moda teve sua primeira edição em um domingo, 2 de novembro de 1851, pretendendo ser um jornal para a publicação de crônicas semanais, sobre o que se passava na vida social e cultural da Corte, além de conter novelas e romances em capítulos, poesias etc. Embora citem muitas pessoas pelo título e nome, as matérias não são assinadas pelos redatores e, quando muito, algumas poesias trazem pseudônimos. Perdurou até o ano de 1853, desaparecendo a seguir.
} 
O hábito genuinamente estrangeiro, trazido para o Rio de Janeiro, somado ao fato de os redatores de um jornal de crônicas semanais, sobre o que acontecia na vida social e cultural da cidade, ensinarem com detalhes a apresentação feminina em visitas, bailes e saraus, evidencia as mudanças que começavam, lentamente, a ocorrer, especialmente para as mulheres que, do confinamento nas alcovas, passavam a atuar com mais frequência nos salões e espaços públicos da Corte carioca.

Algumas décadas depois, nos anos de 1880, a constante chegada de estrangeiros e estrangeiras não só modificava a paisagem das ruas da "velha cidade", nas quais já transitavam mulheres desacompanhadas, mas também os hábitos das elites, pois eram as camadas mais aristocráticas aquelas que consumiam tudo que vinha do exterior, desde os elementos subjetivos como a moda, os hábitos, a literatura, até os materiais, como o simples "papel de Holanda" e "cartas de jogar, seladas, francesas e portuguesas", aos instrumentos médico-cirúrgicos (SENNA, 2006).

Nesse contexto de efervescência e aspiração por tudo que vinha do além-mar, desembarcavam no Cais Pharoux", "[...] cujo nome oficial era Cais do Carmo" (DUNLOP, 1973, p. 61), diariamente, dezenas de estrangeiros vindos de distintos portos europeus e, entre eles, algumas mulheres, cujo papel não era apenas o de acompanhar as aventuras de seus maridos, mas empreender as suas próprias, em uma terra bastante diferente dos reinos que deixavam para trás. Os motivos que as traziam eram os mais variados possíveis: tanto poderia tratar-se da ingênua curiosidade, movida, por exemplo, pela paixão ao estudo da botânica e pela exótica paisagem do novo mundo, quanto da necessidade de recomeçar a vida longe das vicissitudes e perseguições de todas as ordens - mas, sobretudo, as morais e econômicas -, ou ainda, a mais óbvia, a necessidade financeira, que atraía, particularmente, mulheres sem sustentação parental, pelos bons salários anuais pagos às preceptoras, além do fato de trabalharem - o que não era a melhor condição feminina -, longe de parentes e conhecidos em suas cidades de origem.

Uma vez no Rio de Janeiro, normalmente, eram recebidas em seus consulados ou mantinham alguma relação com eles, como demonstram muitos anúncios, desde os que facultavam o endereço oficial para a correspondência entre a candidata e seus contratantes, até os que davam informações sobre a pessoa que anunciava seus préstimos. Assim, aparecem constantemente, nos anúncios, o consulado francês, o consulado alemão, o consulado sueco, o consulado de Portugal e a agência cosmopolita, como nos exemplos a seguir ${ }^{10}$ :

LINGUA FRANCESA. Pessoa habilitada oferece-se a ensinar esta língua, em colégio ou em casa particular, pratica e teoricamente: Dirija-se ao consulado francês, defronte do Passeio Público (ANNUNCIOS, 1879, p. 4, grifo meu).

\footnotetext{
${ }^{8}$ Anúncio colocado no Jornal $O$ Gratis, n. 2, no sábado, dia 13 de abril de 1850, p. 1, da "Nova loja de papel, chá, objetos de escritório, rapé, mate de Paranaguá e muitas miudezas", localizada na Praça da Constituição, canto da rua de S. Jorge, n. 78.

9 "O embarcadouro passou a ser assim chamado por ter existido junto dele, durante longo tempo, um hotel que se celebrizou com o nome de seu proprietário, o francês Louis Adolphe Pharoux, bonapartista ardoroso, natural de Marselha, que aqui aportou em 1815 ou 1816" (DUNLOP, 1973, p. 61).

${ }^{10}$ Optou-se por preservar ao máximo os tipos gráficos em todos os anúncios reproduzidos ao longo do texto, mantendo-se as letras maiúsculas e minúsculas conforme sua disposição no original oitocentista.
} 
PROFESSORA. Distinta e estrangeira ensina português, francês, italiano, alemão, inglês, literatura, história universal, música, desenho e todas as matérias preparatórias; informações, consulado alemão, rua da Alfândega n. 58 (ANNUNCIOS, 1889, p. 7, grifo meu).

PROFESSORA. Uma recém-chegada nesta corte, oferece-se para leccionar português, francês, inglês, alemão, italiano e música, assim como outras matérias escolares. Excelentes recomendações; informações no consulado sueco, rua Theophilo Ottoni n. 51 (ANNUNCIOS, 1889, p. 7, grifo meu).

A preceptora Ina Von Binzer, cujo livro foi publicado por ela mesma quando retornou à Alemanha, após atuar como preceptora no Brasil, é uma importante testemunha da educação doméstica e de seu cotidiano nas Províncias do Rio de Janeiro e de São Paulo. Em seus relatos, ela demonstra ter tido alguns contatos com o cônsul alemão na Corte brasileira, discutindo com ele e sendo por ele aconselhada em suas decisões. A alemã chegou ao Brasil em 1881 e aqui permaneceu até 1884, contratada, inicialmente, para ser preceptora dos filhos da família de um "grande fazendeiro e senhor de escravos" na Província do Rio de Janeiro. De acordo com a sua narrativa, datada de 22 de fevereiro de 1882 (BINZER, 1994), depois de um período nesta fazenda, foi trabalhar em um colégio na Corte até conseguir uma nova colocação, quando é aconselhada pelo cônsul a procurar nas publicações de anúncios do Jornal do Commercio outro lugar de preceptora, em uma fazenda do interior de São Paulo:

Dia 22. Hoje, fui ver o pastor da comunidade daqui e também o cônsul alemão. Foram ambos muito atenciosos e o cônsul, que é um homem esperto e sabe levar os brasileiros na devida conta, aconselhou-me a ir de preferência para a Província de São Paulo, tentar conseguir obter lá uma colocação, pois a que ocupo não é posição para mim; em São Paulo encontrarei também outras colegas. Disse-me isso e ando procurando no Jornal do Comércio o que me possa servir, entre os anúncios de pretos fugidos e vendas de escravos, que é onde também se pedem as professoras com imensa capacidade e inúmeras perfeições (BINZER, 1994, p. 89).

A “colocação" ocupada até então e tida como não sendo uma posição adequada para ela, tratava-se do cargo de professora interna em um dos colégios de meninas existente na Corte no início da década de 1880 , o que pode sugerir que o ofício de preceptora em uma família pertencente à aristocracia urbana ou rural da época gozava de maior prestígio do que o cargo de professora nos colégios particulares, além de ser mais bem remunerado (VASCONCELOS, 2005).

Em suas "cartas", que descrevem a estada na fazenda da Província do Rio de Janeiro, no colégio da Corte, e em outras duas fazendas da Província de São Paulo, a preceptora Ina Von Binzer verifica a prática das famílias da aristocracia e, até mesmo, das camadas médias mais favorecidas economicamente, quanto à educação, principalmente, das filhas mulheres: "As melhores famílias não mandam absolutamente as filhas para os colégios, e devido a isso 
esta sociedade é, em geral, a menos educada ou a mais selvagem que se pode encontrar; exaltam-se, gritam e chegam não raras vezes a ficar com o rosto enrubescido como cerejas" (BINZER, 1994, p. 79).

A prática de contratação de preceptoras era tão usual que, algumas vezes, o anúncio era colocado antes mesmo da chegada da candidata ao país, como mostra o Jornal do Commercio, de 2 de outubro de 1880, quando uma professora alemã, que já atuava como preceptora na Inglaterra, oferece seus préstimos para trabalhar no Brasil, indicando sua "meia idade", característica de preferência das famílias brasileiras, o ordenado de 180 libras anuais, o que, muito provavelmente, não ganhava na Inglaterra, como sugere Monteiro (2000), e a necessidade das despesas de viagem; ou seja, os patrões já pagariam o seu deslocamento, depreendendo-se que viria sozinha, além de destacar suas "melhores recomendações" e a possibilidade de chegar em apenas dois meses:

UMA professora alemã de 32 anos de idade, e que está prestes a concluir a educação de duas atuais discípulas na Inglaterra, deseja encontrar no Brasil emprego como professora em casa de família de tratamento. Sabe leccionar perfeitamente francês, inglês, alemão e um pouco de italiano. Pode começar em Dezembro próximo futuro, e o ordenado é de $£ 180$ por ano e despesas de viagem. Está ao caso de fornecer as melhores recomendações: dirijam-se a Miss Casati Whitehill. Newton Abbott. South Devon. England (ANNUNCIOS, 1880, p. 7).

Contudo, contratar a preceptora no seu país de origem e pagar as despesas da viagem para o Brasil não parece ter sido a prática mais comum a julgar pelos poucos anúncios que são colocados do exterior, ainda que, outros métodos possam ter sido usados para essa negociação direta na Europa, sem passar pelos jornais locais, como a comunicação entre os consulados e a própria indicação de uma para outra, haja vista que, na Inglaterra, por exemplo, Monteiro (2000) infere que havia alguma organização entre as praticantes desse ofício.

Mesmo após já estarem residindo no Brasil, os anúncios demonstram que as preferências das famílias eram por mulheres estrangeiras; o simples fato de ser alemã, francesa ou inglesa era referência suficiente das habilidades para a contratação. Nesse sentido, as mais prestigiadas eram as alemãs, seguidas de suas congêneres francesas e inglesas, mas havendo lugar para quase todas as nacionalidades europeias daquele período.

PROFESSORA francesa ou alemã; Precisa-se de uma para lecionar estes idiomas e mais piano, canto e trabalhos de agulha. É para uma fazenda das de $1^{\text {a }}$ ordem em serra-acima, sendo preciso que as pretendentes deem abonador à sua conduta e moralidade; para tratar, na rua Primeiro de Março n. $47,1^{\circ}$ andar (ANNUNCIOS, 1880, p. 4).

PROFESSORA. Precisa-se para uma fazenda, no município do Rio Preto, de uma professora brasileira ou estrangeira, que saiba ensinar com perfeição português, francês, geografia, piano e trabalhos de agulha; para maiores informações, na rua Municipal n. 5 (ANNUNCIOS, 1880, p. 5). 
Os lugares de preceptoras nas casas "mais capazes" de arcar com os altos custos dessa modalidade eram disputados por ofertas diárias do serviço, que iam desde a informação da nacionalidade às recomendações da conduta e das casas onde já haviam atuado, passando pelos diplomas adquiridos na Europa. O próprio endereço da comunicação já era uma referência do nível da preceptora e, especialmente, do salário a ser cobrado, como sugerem as casas comerciais indicadas nos anúncios, entre elas, elegantes lojas localizadas na rua do Ouvidor, o próprio escritório do Jornal do Commercio, colégios nos quais estavam trabalhando e, menos comum, o próprio endereço. A alusão aos colégios demonstra que era habitual a aspiração, semelhante à da preceptora Ina Von Binzer, de se transferir destes para as casas de família, sugerindo tratar-se de uma ascensão no ofício. Os anúncios, a seguir, são representativos das três nacionalidades estrangeiras mais procuradas e, consequentemente, mais anunciadas pelos periódicos no ano de 1880:

PROFESSORA DE PRIMEIRA ORDEM. Uma senhora alemã que se formou nos conservatórios de Berlim e Leipzig, e que conhece e ensina com perfeição música, piano e canto, (voz contralto), artista em desenho e todos os gêneros de pintura, óleo, aquarela etc., sabendo o francês, inglês e alemão, história, geografia, literatura, geometria, etc, que ensinou com proveito a famílias de alta aristocracia na Alemanha, Inglaterra, Rússia e Suíça, e podendo dar boas informações; deseja ir como professora para alguma casa de tratamento nesta corte ou fora, ou colégio de primeira classe. Carta fechada no escritório desta folha, com as iniciais M. M. W. (ANNUNCIOS, 1880, p. 4).

Professora. Uma professora francesa com prática do magistério, falando as línguas inglesa, francesa e portuguesa, e podendo ensinar música, deseja empregar-se em alguma fazenda; para informações dirijam-se ao colégio Brasileiro, rua das Laranjeiras n. 157 (ANNUNCIOS, 1880, p. 5).

PROFESSORA INGLESA. Uma senhora inglesa, com longa prática de ensino, propõe-se a leccionar em casas particulares, na corte, inglês, francês, alemão e piano: preço módico; para informações, na rua do Visconde do Itaborahy n. 40, Nitherohy (ANNUNCIOS, 1880, p. 5).

Em que pese não haver registros fotográficos conhecidos das mulheres estrangeiras que deixavam seus gélidos países de origem, no inverno, para enfrentar o calor, a insalubridade da cidade, os insetos e os costumes diferenciados que encontravam nos trópicos, Machado de Assis (2017, p. 141), no conto datado de 1870, ao tentar fazer o leitor adivinhar quem é Miss Dollar, descreve uma "[...] inglesa pálida e delgada, escassa de carnes e de sangue, abrindo à flor do rosto dois grandes olhos azuis e sacudindo ao vento umas longas tranças louras [...]", acrescentando que, se soubesse o português, deveria "[...] deliciar-se com a leitura dos sonetos de Camões ou os cantos de Gonçalves Dias [...]”, tendo "o chá e o leite" como a alimentação principal "[...] de semelhante criatura, adicionando-lhe alguns confeitos e biscoitos para acudir às urgências do estômago [...]”. 
Porém, para Machado de Assis (2017, p. 142), “[...] uma tal Miss Dollar seria incompleta se não tivesse óculos verdes e um grande cacho de cabelo grisalho em cada fonte. Luvas de renda branca e chapéu de linho em forma de cuia [...]", o que era para o escritor, a "última demão" na elaboração "deste magnífico tipo de ultramar". Acostumado a descrever seus personagens em minúcias, certamente, buscando inspiração naqueles com quem cruzava no dia a dia (CHALHOUB, 2003), essa deve ser uma das recorrentes imagens de mulheres estrangeiras, vistas pelo escritor, que desceu dos navios nos portos brasileiros para educar crianças e jovens, e que cruzou com ele, apressadamente, pelas ruas da "velha cidade".

A influência dessas mulheres no cotidiano das casas estendeu-se para muito além da educação, criando costumes que foram, pouco a pouco, misturando-se aos da terra, tornandose impossíveis de separar, uns dos outros. Surgidos nas casas, no convívio entre mulheres de diferentes nacionalidades, os hábitos, os valores, as crenças, os castigos, as premiações, os gostos, as práticas presentes na educação doméstica e as formas de aprender e ensinar vão sendo perpetuadas e incorporadas aos rituais educativos, com ressonâncias também nas instituições escolares, que, mais tarde, tornaram-se hegemônicas.

Nesse constante movimento entre a casa e a escola, realizado por mulheres que ousavam ser professoras nas últimas décadas do século XIX, cada vez mais, desloca-se o lugar de status, da esfera privada para os colégios instituídos, reduzindo-se as elaboradas e, notadamente, arrojadas histórias das preceptoras estrangeiras no Brasil, a meros vestígios encontrados em anúncios de jornais oitocentistas.

\section{Nos casarões e sobrados: a educação francesa, ensinada por alemãs e inglesas e aprendida por brasileiras}

Na introdução à tradução portuguesa da obra de Choderlos De Laclos, Da educação das mulheres, escrita originalmente em 1783, Teresa Sousa de Almeida (2002) descreve a surpresa dos viajantes estrangeiros, que chegavam a Paris no século XVIII, com a condição feminina, "única na Europa":

As mulheres pertencentes às classes superiores eram cultas, dirigiam salões, onde trabalhavam na sombra para a glória (ou para a desgraça) de intelectuais e políticos, faziam traduções, escreviam romances, discutiam as novas ideias do tempo, da física à literatura, da astronomia à história, da geometria à filosofia. Sabiam manejar com perícia a arte da conversa, utilizavam sua beleza e a sua cultura para seduzir, eram hábeis e estranhamente manipuladoras (ALMEIDA, 2002, p. 9).

Embora essa condição tenha sofrido reveses no século XIX, com o “[...] peso da tradição sobre aquilo que se esperava de uma mulher - ser a esposa de um homem ou a mãe dos seus filhos" (ALMEIDA, 2002, p. 12), as francesas permaneceram gozando de uma representação de educação feminina superior, especialmente em países periféricos como o Brasil, que tomavam a França por modelo, sendo consideradas "boas" preceptoras, mas, acima de tudo, respeitadas dirigentes de colégios, notadamente, para meninas, tarefas a que muitas se dedicaram, principalmente na Corte carioca. 
No que se refere às preceptoras alemãs, sua precedência no gosto dos brasileiros sobre as francesas está justamente relacionada à citação anterior, pois ainda que as mulheres vindas do território germânico tivessem uma excelente educação feminina para a época, o padrão de obediência e disciplina era o diferencial que as tornava extremamente requisitadas para ensinar crianças das camadas da população mais favorecidas social e economicamente. Bernardes (2000), citando uma escritora anônima, possivelmente, autora do opúsculo As mulheres, publicado na Bahia em 1887, narra um trecho da obra:

A Alemanha, por exemplo, mantendo uma adiantada educação feminina, tem uma legislação hostil aos interesses das mulheres e está trezentos anos atrasada nesse sentido. Pela lei prussiana só o consentimento do pai é necessário para o casamento dos filhos. Se a mulher é espancada mas não oferece perigo de morte não pode solicitar divórcio e na Baviera a lei até permite ao marido espancar a mulher com moderação. Os ganhos da mulher, durante o casamento, pertencem somente ao marido (BERNARDES, 2000, p. 37).

Talvez o fragmento acima possa dar alguma pista da chegada de um grande número de mulheres alemãs para exercer o ofício de preceptoras no Brasil, além da adaptação a essa função e de sua permanência ao longo de décadas. Em que pese não serem as únicas nacionalidades em ascensão no mercado da educação doméstica, presente nos anúncios oitocentistas, pois é possível encontrar italianas, portuguesas, suecas e inglesas em profusão, eram as alemãs e as francesas que pareciam ter atrelado às suas próprias características o conceito da preceptoria no final do oitocentos.

As inglesas, apesar de aparecerem mais relacionadas às "lições por casas", também eram reconhecidas naquilo que Jinzenji (2010, p. 153) cita como o exemplo da preceptora Jane Marcet com sua "discípula Caroline", discutindo temáticas mais elaboradas como propriedade, economia e política, numa época em que surgiam as primeiras sufragistas ${ }^{11}$ (NASH, 2004) e, portanto, causavam certo receio às famílias, cujas moças casadoiras, tinham limites no que aprender. No entanto, as peceptoras inglesas que vieram para o Brasil, atentas ao que era esperado pelas famílias, atuavam dentro do modelo em que prevalecia a "tradição" estável até a Inglaterra pré-moderna, na qual, segundo Pollock (2010, p. 25), “[...] as meninas deviam ser transformadas no ideal de feminilidade descrito nas escrituras: casta, silenciosa, obediente". De acordo com Quintaneiro (1996, p. 109), “[...] à medida que avançava o século XIX, a mulher de classe média inglesa era mais e mais envolvida pelo discurso apologético da maternidade como fonte máxima de prestígio feminino [...]" e pelo ideal da mulher dedicada inteiramente às tarefas domésticas, às quais um grande número de "publicações científicas e sermões" visavam converter em "deveres femininos".

Além disso, muitos pais, em países como a Inglaterra, França e Alemanha, preocupados com o "estigma das solteironas", causado pelo maior número de mulheres em relação aos homens, durante todo o século XIX, considerando as guerras, a migração para as colônias e o alto custo do matrimônio, entre outros aspectos - o que, muitas vezes, foi o

\footnotetext{
11 “O sufragismo britânico dividiu-se numa vertente moderada, conhecida como a corrente constitucionalista que surgiu na década de 1860, e numa vertente radical de actuação directa que emergiu em 1903” (NASH, 2004, p. 116).
} 
motivo que levou à profissão de governantas -, tomavam providências para que suas filhas aprendessem a ler e a escrever e tivessem uma boa educação, a fim de que, depois, não casando, pudessem atuar como preceptoras, "[...] cuja presença tornou-se cada vez mais comum nos lares”, conforme atesta Quintaneiro (1996, p. 156):

$\mathrm{Na}$ verdade, trata-se de um expediente há muito utilizado pela aristocracia rural inglesa que, longe de desaparecer sob o peso das transformações decorrentes do desenvolvimento industrial, fora ganhando prestígio aos olhos da burguesia, que o adotou como marca de distinção, de modo que a prática manteve-se durante muito tempo. Em 1851 contavam-se na Inglaterra mais de 21.000 mulheres dedicadas às atividades de professora e governanta, a maior parte das quais era solteira. [...] Eis aí a fonte inesgotável de governantas e professoras que a solteirona - a deficiente - virá alimentar a troco de salários quase miseráveis, já que um dos únicos empregos socialmente acetáveis, sem conhecimento especializado ou experiência, era ensinar. Elas viriam a formar outras moças a partir de seu próprio limitado espectro de conhecimentos. Pode-se imaginar o quanto muitas delas, representantes em carne e osso do estado mais execrado pelas jovens aspirantes ao casamento, seriam motivo de pilhéria ou de comiseração por parte da literatura da época ou mesmo de suas pupilas (QUINTANEIRO, 1996, p. 156 e 158).

Para aquelas que se encontravam nessa situação, cruzar o Atlântico, não representava um perigo, mas, talvez, uma possibilidade de libertação e ascensão. O viajante Carl Schelichthorst, citado por Leite (1984, p. 115-116), falando acerca das "mulheres públicas", repara que no Brasil testemunhou "exemplos surpreendentes", em que essas mulheres escondiam sua "vergonha sob o luxo e elegância". Nessa mesma perspectiva, acrescenta que, para as estrangeiras, moças de boa família e bem educadas, então, não era de admirar que se sentissem "atraídas por esse país, onde conseguem um grau de fama e riqueza, que na Europa jamais atingiriam pelo mesmo caminho".

No Brasil, alemãs, francesas, inglesas e também mulheres de outras nacionalidades europeias, cada uma com suas características percebidas como um "rótulo" e gozando das vantagens advindas dessas mesmas ideias preconcebidas sobre a preceptora estrangeira, encontravam no país um mercado promissor e em ascensão para seus serviços, como demonstram os anúncios diários de procura por essa colocação nos jornais da Corte.

Uma vez encontrado o emprego esperado - como se presume tenha sido o que ocorreu após o anúncio do dia 24 de junho de 1880 do Jornal do Commercio, no qual um pai de família faz publicar: "A senhora alemã de meia idade, que anunciou por este jornal querer ir para uma fazenda, mandando deixar carta a C. B., queira dirigir-se à rua Primeiro de Março n. 47, $1^{\circ}$ andar" (ANNUNCIOS, 1880, p. 6) -, normalmente, chegava-se a casa onde a atividade de preceptoria seria exercida, na Corte ou em uma Fazenda do interior da Província.

O casarão de cinco portas no primeiro pavimento, sendo a maior, situada no meio, para a entrada das carruagens, e seis janelas no andar acima, guardadas por um pequeno balcão; ou o sobrado de mesmas proporções, cuja diferença era o comércio ou a oficina no andar térreo que legavam para moradia a sobra do andar superior, daí o nome "sobrado" 
(FREYRE, 2003; COSTA, 2015), são exemplos das casas em que as mulheres estrangeiras ingressavam como preceptoras ou governantas, a partir de sua escolha, seja por um emprego que as sustentasse, seja por uma vida longe do lugar de onde provinham.

Cruzando pesadas portas e subindo íngremes escadas, de forma usual, deparava-se com crianças, notadamente meninas, que pouco saíam dos ambientes domésticos, bastante confinadas às amas, aos brinquedos artesanais, às superstições, às rezas, às gulodices, não indo além das janelas entreabertas, em sua curiosidade pela rua. Também nas fazendas, localizadas em alas estrategicamente separadas, as meninas eram constantemente vigiadas por inúmeras escravas, mesmo quando passeavam pelos arredores, sobretudo, tratando-se de estâncias produtoras de café, onde transitavam centenas de escravos, capatazes, ensacadores, transportadores, comerciantes, caixeiros, visitantes etc., com suas mulas, cavalos, carros de bois, carroças, em um cotidiano muito bem descrito pela viscondessa de Arcozelo (1887), dona de fazendas cafeeiras no Vale do Paraíba, no seu diário relativo ao ano de 1887 - ela mesma tendo uma preceptora portuguesa para os filhos ${ }^{12}-$, mas que, certamente, não era o cenário para as andanças das meninas da casa.

No interior da residência, com bastante sorte, apresentava-se ao visitante, algo como o que descreve Machado de Assis (2001):

Era uma vasta sala, dando para a chácara, por meio de seis janelas de grade de ferro, abertas de um só lado. Todo o lado oposto estava forrado de estantes, pejadas de livros. Estes eram, pela maior parte, antigos, e muitos infólios; livros de história, de política, de teologia, alguns de letras e filosofia, não raro em latim e italiano (ASSIS, 2001, p. 25).

Embora essa fosse uma descrição bastante promissora das possibilidades da casa, em grande parte das circunstâncias, a residência senhoril era desprovida de qualquer livro a não ser a Bíblia; e as próprias preceptoras é que traziam seu material de trabalho, ou acertavam com a família aquilo que deveria ser adquirido para a educação das meninas.

Cabe notar que a revista Instrucção Nacional: Revista de pedagogia, sciencias $e$ letras $^{13}$ publicava, no ano de 1873, a relação das Bibliotecas do Município da Corte, demonstrando uma quantidade razoável de acervos, os quais, talvez, fossem atrativos para a busca de material, por mulheres estrangeiras no exercício de suas ocupações de preceptoras no Brasil. A matéria assinalava:

Há na cidade do Rio de Janeiro 17 bibliotecas, a saber: $1^{\text {a }}$, a pública, com 53.608 obras em 115.980 volumes, 2.500 manuscritos, 905 mapas, cartas e plantas; $2^{\mathrm{a}}$, a da marinha, com 7.500 obras em 23.681 [volumes], inclusive 41 manuscritos; $3^{\mathrm{a}}$ a do Gabinete portuguez, com 24.440 obras em 51.621 volumes; $4^{\mathrm{a}}$, a da Britsh Subscription Library (particular), com $3.561 \mathrm{em}$ 8.944 volumes: $5^{\mathrm{a}}$, a da Academia das Belas Artes, com 834 volumes; $6^{\mathrm{a}}$, a da Escola Central; $7^{\mathrm{a}}$, a do Museu Nacional; $8^{\mathrm{a}}$, a do Instituto Histórico, com

\footnotetext{
12 Sobre o assunto, ver Vasconcelos (2015).

${ }^{13}$ Instrução Nacional: Revista de pedagogia, sciencias e letras, era dirigida por Antônio Estevam da Costa e Cunha e Augusto Cândido Xavier Cony. Publicada no Rio de Janeiro, era impressa pela Typographia de Quirino F. de Espírito Santo, durante os anos de 1873 e 1874.
} 
3.605 volumes, 193 mapas e cartas e 272 manuscritos; $9^{\text {a }}$, a do mosteiro de S. Bento, com 8.000 volumes; $10^{\mathrm{a}}$, a do convento do Carmo, com $4.000 ; 11^{\mathrm{a}}$, a da faculdade de medicina, com 5.181; 12a a da sociedade Ensaios Litterarios, com 2.600; $13^{\mathrm{a}}$, a da sociedade Typographica Fluminense, com 557; $14^{\mathrm{a}}$, a da Associação Germânica, com 5.422; $15^{\mathrm{a}}$, a da sociedade Retiro Litterario Portuguez, com $1.813 ; 16^{\mathrm{a}}$, a da diretoria geral da Estatística, com $1.103 ; 17^{\mathrm{a}}$, a municipal, que começa agora a prover-se de livros (BIBLIOTHECAS DO MUNICÍPIO DA CÔRTE, 1873, p. 46).

A par do que havia nas bibliotecas da Corte, bem como do catálogo relativamente variado de títulos de livros existentes nas livrarias da cidade, o que era também constantemente anunciado pelos jornais - tanto com volumes dedicados a ensinar meninos quanto meninas, ou ambos -, possivelmente foi a esses expedientes que recorreram as preceptoras estrangeiras para complementar o material pedagógico de que dispunham em sua bagagem na chegada ao Brasil. Vale ressaltar que os ensinamentos dados aos meninos se distinguiam dos ofertados às meninas, embora compartilhassem, principalmente do ensino das línguas, da gramática, do catecismo, de literatura e de história. Às meninas, desde a mais tenra idade, eram ensinadas especificidades, julgadas essenciais para o sexo feminino.

Para as meninas, havia conhecimentos específicos a serem aprendidos como bordar, coser, marcar, cortar, dançar, trabalhos de agulha, caia a ouro, prata, matiz e escama de peixe, tricot, filot, flores, obras de fantasia, recortar estofos, veludos e outros trabalhos manuais, que eram oferecidos para serem ministrados por professores particulares e preceptores (VASCONCELOS, 2005, p. 76).

Além desses conhecimentos característicos que reuniam conteúdos a habilidades, ao longo de toda a segunda metade do século XIX, houve uma crescente procura por "manuais para o lar", como indispensáveis à educação feminina, sobretudo àquela realizada na esfera privada, com regras e receitas de economia doméstica, para ensinar às meninas, às moças e às futuras mães de família a gerir a casa (MALTA, 2011, p. 43). Embora fossem amplamente usados como roteiro para a educação ministrada na casa, alguns desses manuais faziam parte até mesmo do programa de colégios femininos existentes na Corte e de algumas escolas de instrução pública para meninas.

Um exemplo do conteúdo desses manuais pode ser acompanhado no periódico Bazar Litterário: de educação e de recreação ${ }^{14}$, publicado no Rio de Janeiro, no ano de 1878, o qual trazia uma série de matérias divididas em capítulos quinzenais, intituladas "Doutrina sobre o governo da casa", cujo objetivo, segundo os redatores, era oferecer um complemento à "educação da donzela, no colégio e na família". As matérias não estão assinadas, mas possuem uma referência ao final de cada capítulo: "La science du ménage" "15. Essa referência evidencia que o conteúdo era copiado e traduzido do livro original em francês, de Adrien

\footnotetext{
${ }^{14}$ De acordo com os Anais da Biblioteca Nacional, vol. 85, 1965, a revista quinzenal Bazar Litterário: de educação e de recreação foi publicada de $1^{\circ}$ de outubro de 1878 a 15 de junho 1879, no Rio de Janeiro, pela Typographia de São Vicente de Paula.

15 "A ciência da casa".
} 
Sylvain (1826-1914), "La science du ménage: complément de l'éducation de la jeune fille au pensionnat et dans la famille/par l'auteur des Petites vertus et des Paillettes d'or", publicado por Lévis Mercier, em Québec. Embora haja dúvidas quanto à data da publicação, certamente foi anterior a 1878, ano em que é traduzido no Bazar Litterário, podendo dar uma ideia daquilo que se esperava das preceptoras estrangeiras, além de prover a educação elementar das crianças e o aprendizado das disciplinas básicas.

Segundo Deroisin (1997), o isolamento das propriedades, quando localizadas fora da zona urbana, o excesso de riqueza e de ociosidade, os caprichos, as peculiaridades da mestra, da dona da casa, a comitiva de servos - no Brasil, de escravos - davam "o tom" para o cenário em que as meninas eram educadas pelas governantas estrangeiras, no qual se incluíam, muitas vezes, pais ausentes, indiferentes ou desolados por doenças ou tédio, "de uma vida perdida", além de mães que se sentiam incapazes, elas mesmas, de ensinar suas filhas, seja pela deficiência de sua própria educação, seja porque esperavam algo mais de acordo com aquilo que esses mesmos estrangeiros introduziam como modelo de comportamento no Brasil. Assim, a maneira mais prática para reparar ou suprir essa lacuna na família era buscar "[...] no reino das governantas, professoras, preceptoras" (DEROISIN, 1997, p. 130), tanto no interior da Inglaterra, em Paris, ou nos territórios germânicos, mulheres capazes de, sem correr o risco de testemunharem para a sociedade local o estado em que encontraram as crianças e mesmo a casa, tornarem as meninas educadas para a apresentação pública, o casamento e a gestão do lar, a ponto de serem lisonjeadas em suas maneiras e caprichos, moldados por uma artífice estrangeira.

Com efeito, o objetivo maior de contratar mulheres que já haviam vivido no "berço" da civilização, em contato com o que havia de mais sofisticado, era que ensinassem, explicassem e colocassem em prática um programa de educação que pudesse transformar as meninas brasileiras em mulheres educadas, adequadamente, conforme o padrão europeu. O livro de Adrien Sylvain, "La science du ménage: complément de l'éducation de la jeune fille au pensionnat et dans la famille...", copiado, traduzido e publicado em capítulos no Bazar Litterário, é um exemplo de manual usado para essa finalidade, entre tantos outros encontrados, nas últimas décadas do oitocentos, em jornais, revistas e livros. A sessão intitulada Educação - Recreação introduzia o livro traduzido, designando seu escopo e utilidade. Contudo, logo se percebe que não bastava lêlo; era preciso entender como colocar em prática ensinamentos tão distanciados da realidade brasileira. E para isso, mais do que traduzi-lo, era necessário alguém que pudesse compreender o exato sentido da "doutrina" apresentada.

DOUTRINA SOBRE O GOVERNO DA CASA E TRABALHOS DOMÉSTICOS. COMPLEMENTO DA EDUCAÇÃO DA DONZELA, NO COLÉGIO E NA FAMÍLIA. INTRODUCÇÃO. I. Este livrinho contém muitas explicações circunstanciadas, que hão de parecer minuciosas à Donzela estouvada, e que talvez a farão sorrir, com o ar desdenhoso que, graciosa, manifesta quando recebe lições que lhe parecem superiores á sua inteligência. - Explicações de trabalhos domésticos, quando se tem dezesseis anos, que o coração tem asas, e a imaginação nos faz entrever junto de nós, através de florescente atmosfera, o encantador futuro que idealizamos! - Esclarecimentos sobre miudezas caseiras, prosaísmo material, dirigido a nós, donzelas, que sentimos nossa alma elevada pela poesia, acima das realidades da existência! (DOUTRINA SOBRE O GOVERNO DA CASA, 1878, p. 16). 
O Bazar Litterário, ao versar para o português a obra estrangeira, pretendia introduzir padrões de conduta, referindo-se ao exemplo das mães, as quais deveriam ser lembradas como já praticantes das regras estabelecidas no governo da casa, a ponto de ser dito: "Desejamos a todas as moças que achem aqui retratado o caráter da sua mãe!" (DOUTRINA SOBRE O GOVERNO DA CASA, 1878, p. 17), Todavia, no Brasil, provavelmente, poucas mães de famílias haviam ouvido falar de tais regras tão detalhadas e minuciosas, iniciadas pela pergunta: "em que consiste o conhecimento do governo da casa e economia doméstica?", respondida, a seguir: "é a arte de empregar para a utilidade e bemestar da família os recursos que a Providência nos proporciona".

$\mathrm{O}$ autor francês afirma, ainda, que os ensinamentos não se limitam à "cozinha, galinheiro, etc.”, mas ensinam "[...] a ajuntar, conservar, aproveitar, consertar, embelecer; isto é, o complexo de virtudes humanas, cuja reunião se encaminha a fazer a vida da terra tão feliz como é possível ser" (DOUTRINA SOBRE O GOVERNO DA CASA, 1878, p. 17-18). Logo, em seguida, a "primeira lição" enfoca a missão da mulher na família e as qualidades necessárias ao cumprimento dessa missão, lembrando que "a felicidade da família depende quase exclusivamente da mulher, a quem pertence o governo do pequeno reino doméstico" (Ibidem). Entre suas tarefas que faziam parte da missão estava a de "revistar as pessoas e cousas, como um general passa revista à tropa: não consentir que as cousas estejam fora de seu lugar, exigir o maior asseio" e "ter em eminente grau o espírito de ordem e de bom gosto", finalizando com a afirmação de que "ela deve, como rainha, louvar e recompensar, repreender e punir, afervorar a todos com seu exemplo. Enfim, semelhante a uma mãe, deve comunicar alegria à família, ter minucioso cuidado da saúde de todos" (DOUTRINA SOBRE O GOVERNO DA CASA, 1878, 18-19). O autor recomendava: "recorrei a vossa mãe" e pedi-lhe "o favor de vos ensinar a difícil e importante arte de governar casa" (Ibidem).

No entanto, quando as próprias mães não tinham recebido instrução suficiente ou específica para essa "arte", a opção para educar as meninas da casa eram as preceptoras ou governantas; preferencialmente, estrangeiras. Além disso, o livro traduzido de Adrien Sylvain fazia uma crítica às demais disciplinas: "a gramática, a análise, a história, a geografia”, pois para ele só teriam "utilidade vaga e restrita". A ciência do governo da casa é que ajudaria "todos os dias a proceder com prudência e madureza", e somente este gênero de conhecimentos é que era "especialmente feminino" (DOUTRINA SOBRE O GOVERNO DA CASA, 1878, p. 20). Citando os conselhos de madame Julia Borde, acrescentava o autor:

[...] é preciso que a mulher aprenda tudo que é relativo aos trabalhos domésticos; convém que saiba como se faz um jantar, as honras da mesa, que precauções convém adotar para abastecer a casa, o preço exato dos comestíveis, e a quantidade d'estes necessária para determinado número de pessoas. Não é menos importante conhecer as regras econômicas, com que se faz em casa algumas obras com pequena despesa, as quais tem alto preço quando se encomendam. Haverá talvez pessoas que julgam rebaixar a fidalguia consentindo que suas filhas se ocupem d'estes trabalhos caseiros. Que erro! Os conhecimentos que dizem respeito à economia de uma casa são indispensáveis à educação da mulher, tanto como a leitura e a escrita. [...] Não existe posição social (a experiência o tem provado), que possa eximi-la de cozinhar um dia, de lavar, coser seus vestidos e roupa branca, de limpar e 
arrumar seu aposento. A natureza a constituiu compradora, mestra e enfermeira dos membros de sua família. Seu desdém ou ignorância da direção da casa e trabalhos domésticos, e de todos os deveres que tornam as mulheres úteis, respeitáveis, necessárias, provam má educação, e alma pouco elevada (DOUTRINA SOBRE O GOVERNO DA CASA, 1878, p. 21).

Em uma sociedade na qual todo trabalho doméstico era feito por escravos, tais lições além de encontrar certa resistência das próprias mães, indicavam a necessidade de auxiliares para educar as filhas nesses preceitos, capazes de decifrar tais códigos, muitas vezes inteligíveis às senhoras das camadas abastadas da população brasileira oitocentista.

$\mathrm{Na}$ continuação da tradução do livro de Adrien Sylvain, constante do Bazar Litterário, como "Doutrina sobre o governo da casa", a primeira parte da obra, intitulada "Administração e aumento da renda na família", era composta por cinco regras, dispostas hierarquicamente, a partir das quais as discípulas aprendiam a economia doméstica. A primeira regra descrita após o preâmbulo tratava de "saber a renda que se tem, e regular a despesa conforme esta", aconselhando as donas da casa como poupar os gastos e regular as despesas, sendo que uma das primeiras indagações era: “[...] não há superfluidades de vaidade literária, assinar jornais fúteis, e de modas, que apenas se folheiam e que só servem para se fazer ostentação d'eles? Suprimi seis meses estes jornais, fareis verdadeira economia de tempo e dinheiro" (DOUTRINA SOBRE O GOVERNO DA CASA, 1878, p. 47). Continuava a tradução recomendando às moças que em vez do bordado, "que vos conserva indolente e pensativa" (Ibidem), consertassem a roupa usada, cortassem e fizessem seus vestidos, poupando assim o pagamento da costureira. Para mulheres que dificilmente tinham qualquer noção contábil das rendas com as quais viviam, parecia extremamente inútil um ensinamento para o qual elas poderiam contribuir muito pouco, considerando que, normalmente, as mulheres das elites desconheciam não só as rendas, o patrimônio, mas também as dívidas e penhores de seus maridos.

A segunda regra versava sobre "saber comprar, e comprar cada coisa oportunamente", chamando a atenção para o fato de o autor, tão distante da realidade brasileira, traduzido para nossas patrícias, afirmar: "não mandeis comprar por outrem, sendo possível: ficareis mais satisfeita, e sabeis melhor do que os outros o que vos convêm" (DOUTRINA SOBRE O GOVERNO DA CASA, 1878, p. 97). Em um país, onde as brasileiras dificilmente saíam às ruas e as compras da casa eram feitas pelos homens, bem como as aquisições pessoais, ou eram realizadas por meio de amostras ou os mercadores é que iam até as compradoras, colocar em prática tal hábito implicava inúmeras dificuldades. Nas palavras de Quintaneiro (1996, p. 83), “[...] o costume de fazer compras, associado nas sociedades europeias e na norte-americana aos prazeres desfrutados pelo sexo feminino, era desconhecido no Brasil”.

A terceira regra da "Doutrina sobre o governo da casa" ensinava a "vigiar tudo, evitar os pequenos desperdícios". Se as regras anteriores, provavelmente, encontravam dificuldades de serem compreendidas pelas brasileiras, essa era facilmente assimilada, e nas casas por onde transitavam dezenas de parentes, agregados, visitantes, escravos domésticos, não raro são descritas mulheres com um molho de chaves pendurado à cintura, guardiãs atentas dos baús, das cômodas, dos armários e das despensas, nos quais ficavam "protegidos" 
doces, frutas, biscoitos, carnes, ovos, leites e quaisquer comestíveis, bem como rendas, lãs, linhas, fitas, tecidos, papéis, santos, terços, rolos de fumo, velas, produtos vendáveis, com rigorosa vigilância sobre, particularmente, os escravos que os manuseavam, com muitos relatos de casas, em que esses comiam apenas sobras e lavagem, além de receberem castigos por pequenos furtos de comida (FREYRE, 1997; 2003; 2010).

A quarta regra recomendava "procurar ensinar bem os criados". Em um cotidiano observado por viajantes, no qual a força do trabalho dos escravos era usada para "reforçar a economia doméstica" (QUINTANEIRO, 1996), com os escravos de ganho, é provável que os ensinamentos fossem entendidos como uma forma de fazer com que as habilidades fossem comercializadas. Quintaneiro (1996, p. 55) cita o testemunho de um missionário que teria ouvido uma brasileira de "alta classe" declarar "[...] ter perdido inteiramente a sua saúde na interessante ocupação de repreender negrinhas, de que possuía algumas dezenas, e não conhecia que tarefa lhes dar a fim de evitar que vadiassem".

A quinta e última regra da primeira parte do livro de Adrien Sylvain, referia-se a "distribuir seu dia com sabedoria". A manhã deveria ser, inicialmente, dedicada à oração: "a oração irá fortalecê-la para a luta, isso irá protegê-la de muitos perigos", portanto, ensinava o autor: “[...] só muito raramente e por razões sérias, deixe seu quarto, não tendo rezado de joelhos". A tarde deveria ser dedicada às visitas, à correspondência, aos diferentes trabalhos manuais "só ou em companhia, ou aos estudos que se continuam". À noite, de acordo com o autor, era destinada ao descanso e ao "recreio", entendido por ele como a música, os jogos, a conversação e as leituras agradáveis, "sempre que seja possível, na intimidade tão doce da vida de família” (DOUTRINA SOBRE O GOVERNO DA CASA, 1879, p. 210).

Ao recolher-se ao quarto, além das orações carregadas de penitências e lástimas, destaca-se o fato de o autor sugerir que as mulheres pudessem escrever algumas páginas do seu "jornal”, palavra traduzida, sem muita precisão, do original, que, na verdade, significava um "diário" de anotações. Tal informação revela que, possivelmente, o hábito de manter um diário como o da viscondessa de Arcozelo, e de muitas de suas contemporâneas, devia-se à educação francesa que estimulava essa prática (VASCONCELOS, 2014; 2015). Todavia, a intensa censura das preceptoras, das governantas, das mães, das próprias autoras e, posteriormente, das famílias que os herdaram, impediram que significativos exemplares desse tempo e contexto chegassem até nós.

O viajante Hebert Smith, em relato datado de 1873 (apud LEITE, 1984, p. 77), afirma que "[...] a maioria dos estrangeiros nunca chega a conhecer a vida íntima do Rio". Talvez, as únicas exceções a essa constatação fossem as peceptoras, que adentrando os casarões, os solares, as fazendas, para exercer seu ofício, acabavam por privar de uma intimidade não permitida a nenhum outro forasteiro. A par desse privilégio, poucas souberam registrar e eternizar suas memórias, fossem elas francesas, alemãs, inglesas. Contudo, provavelmente, todas elas viveram e/ou estiveram presentes em situações repletas de espanto, surpresa, emoção, indignação, medo, alegria, comiseração, diante de mundos tão diferentes que se reuniram para aquela que era uma das mais importantes realizações nas famílias de mulheres pertencentes às elites oitocentistas: prepará-las e educá-las para um bom casamento. 


\section{Finalizando: em busca de vestígios das preceptoras estrangeiras}

As duas últimas décadas do século XIX mostram um país que se modificava em muitos aspectos; porém, permanecia, em tantos outros, da mesma forma que em seu passado colonial. A educação feminina estava entre esses aspectos, cuja mudança foi ocorrendo de maneira mais lenta, arraigada a profundos tabus e preconceitos relativos à mulher, que precisariam de mais de um século para serem debelados. As mulheres estrangeiras, que aqui chegaram nas últimas décadas do oitocentos, não estavam isentas desses preconceitos, mas eram consideradas "diferentes", aceitáveis em seus hábitos inapropriados para as brasileiras, porque estavam de passagem; eram apenas visitantes, cujos serviços específicos tornavam-se necessários somente naquele momento.

Ainda assim, olhando as imagens do século XIX, causa certo espanto a coragem e a determinação empreendida pelas viajantes estrangeiras que vieram ser preceptoras no Brasil do oitocentos, especialmente quando se constatam as condições das travessias em navios, que podiam levar mais de um mês para cruzar o Atlântico, vindos do norte da Europa; até o desembarque e a chegada ao Rio de Janeiro, onde as mulheres "honestas" não saíam desacompanhadas às ruas e as próprias ruas eram "[...] mal traçadas, as calçadas, quando existiam, imperfeitas; e havia o perigo de serem atropeladas pelos carrinhos e carruagens" (QUINTANEIRO, 1996, p. 75). Além disso, tinham de enfrentar as acomodações que, quando não apresentavam alto custo, eram consideradas pouco adequadas, pelos viajantes que por elas passaram. Some-se a isso tudo, a imensa rede de "mulheres públicas" que enchia as ruas centrais da cidade, com "uma tal acumulação de prostitutas, sem controle algum", que se constituía "um verdadeiro perigo para a saúde pública", como testemunham os viajantes Louis e Georges Verbrugghe, em 1878 (LEITE, 1984, p. 117).

Nessa cidade, onde as mulheres de família levavam sua existência urbana por trás das janelas e dos balcões, centenas de destemidas estrangeiras ousaram aportar sozinhas - a julgar pela quantidade e pela frequência de anúncios -, em busca de um emprego; bem como sozinhas fizeram as tratativas do contrato de trabalho, sujeitando-se a residir em lugares isolados e distantes, com o propósito de atuarem como governantas nas casas das famílias que podiam pagar o alto custo de seus serviços. Enquanto em Londres estavam sujeitas a salários miseráveis, no Brasil, vão encontrar um "paraíso" descrito pelos viajantes, para essa atividade, em uma sociedade ávida pelo padrão europeu de civilização e luxo, embora sem querer abrir mão de nenhuma das peculiaridades brasileiras que a tornava tão diferente e exótica em relação ao seu aspirado modelo.

No período em que se faziam e desfaziam teorias sobre a obrigatoriedade do ensino, a importância da escolarização, o papel da escola, há muito elas já atuavam de casa em casa, adaptando-se às famílias, às aspirações, aos métodos preferidos pelos pais, às características das discípulas, às humilhações e às homenagens, às diferenças de tratamento, às paisagens, ao movimento das casas, àquilo que não compreendiam e àquilo que compreendiam muito bem, mas não podiam alterar, como a forma com que eram vistas: estrangeiras, solteiras, destinadas à vida de professoras, errantes pelo mundo para ganhar seu próprio sustento.

Alguma delas, no Brasil, terá modificado essa história e o seu fim? Não se sabe. E, dificilmente, se saberá, pois além de sofrerem a discriminação comum às mulheres estrangeiras daquela época, que se moviam para além do papel a que estavam destinadas, 
também a historiografia tratou de invisibilizá-las, referindo-se quase tão-somente à escola, na qual por pouco tempo elas puderam atuar, pois, em todas as Províncias, uma das condições para ser admitido como professor público, conforme os regulamentos promulgados, era a de ser cidadã ou cidadão brasileiro e estar no gozo de seus direitos civis e políticos, além da conduta regular. Restava às preceptoras rumar de volta à Europa.

Por aqui, seus vestígios foram sendo apagados e acabaram por se limitar a frases em cartas de viajantes, fragmentos soltos em diários, observações em manuais. Contudo, também permaneceram em centenas de anúncios que aparecem, exibem-se e se misturam nas páginas dos jornais oitocentistas.

Ainda pouco explorada, a educação doméstica não logrou, até então, dar a esses vestígios lugar de destaque para recontar a história da educação, que se fez antes, de forma paralela, e depois da escola, e que transmitiu a ela muitas de suas práticas, fazendo com que a vinda das preceptoras para o Brasil, sua estada, seus ensinamentos e seu legado sejam apenas mais uma entre as "curiosidades" adormecidas no oitocentos.

\section{Referências}

ALBUQUERQUE, Samuel Barros de Medeiros. Memórias de Dona Sinhá. Aracaju: Typografia Editorial/ Scortecci Editora, 2005.

. Nas memórias de Aurélia: cotidiano feminino no Rio de Janeiro do século XIX. São Cristóvão: Editora UFS, 2015.

ALMEIDA, Teresa Sousa de. Prefácio. In: LACLOS, Choderlos de. Da educação das mulheres. Lisboa: Antígona, 2002.

ANNUNCIOS. Jornal do Commercio, Rio de Janeiro, p. 4, 4 jan. 1879.

ANNUNCIOS. Jornal do Commercio, Rio de Janeiro, p. 5, 30 jan. 1880.

ANNUNCIOS. Jornal do Commercio, Rio de Janeiro, p. 5, 14 fev. 1880.

ANNUNCIOS. Jornal do Commercio, Rio de Janeiro, p. 4, 27 mar. 1880.

ANNUNCIOS. Jornal do Commercio, Rio de Janeiro, p. 4, 10 abr. 1880.

ANNUNCIOS. Jornal do Commercio, Rio de Janeiro, p. 5, 13 abr. 1880.

ANNUNCIOS. Jornal do Commercio, Rio de Janeiro, p. 6, 24 jun. 1880.

ANNUNCIOS. Jornal do Commercio, Rio de Janeiro, p. 7, 2 out. 1880.

ANNUNCIOS. Jornal do Commercio, Rio de Janeiro, p. 7, $1^{\circ}$ jan. 1889.

ANNUNCIOS. Jornal do Commercio, Rio de Janeiro, p. 7, 15 jan. 1889.

ASSIS, Machado de. Mulheres de Machado. São Paulo: SESI-SP Editora, 2017.

. Casa velha. Rio de janeiro: Expressão e Cultura, 2001.

BARROS, José D’Assunção. Cidade e história. Petrópolis: Vozes, 2007.

BERNARDES, Maria Thereza Caiuby Crescenti. Escritora anônima. In: MUZART, Zahidé Lupinacci (Org.). Escritoras brasileiras do século XIX. Florianópolis: Editora Mulheres, 2000. 
BIBLIOTHECAS do Município da Côrte. Instrucção nacional: Revista de pedagogia, sciencias e letras. Rio de Janeiro: Typographia de Quirino F. de Espírito Santo, 1873. (2. ed. 1873-1874).

BINZER, Ina Von. Os meus romanos: alegrias e tristezas de uma educadora no Brasil. 6. ed. Rio de Janeiro: Paz e Terra, 1994.

BRIERLY, Oswald. Diários de viagem ao Rio de Janeiro: 1842-1867. Rio de Janeiro: Andrea Jakobsson Estúdio, 2006.

CAMURÇA, Zélia Sá Viana. Mulheres viajantes no Brasil, século XIX. Fortaleza: Gráfica e Editora Pouchain Ramos, 2012.

COSTA, Flaviano Menezes. Moradas e memórias. São Luís: EDUFMA, 2015.

COSTA, Hebe Canuto da Boa-Viagem de Andrade (Org.). Elas vieram de longe: séculos XIX e XX. São Paulo: Scortecci, 2010.

CHALHOUB, Sidney. Machado de Assis: historiador. São Paulo: Companhia das Letras, 2003.

CHATAIGNIER, Gilda. História da moda no Brasil. São Paulo: Estação das Letras e Cores, 2010.

DEL PRIORE, Mary. Prefácio. In: FRANÇA, Jean Marcel Carvalho. Mulheres viajantes no Brasil (1764-1820). Rio de Janeiro: José Olympio, 2008.

DEROISIN, Sophie. Petites filles d'autrefois. Paris: Api, 1997.

DOUTRINA sobre o governo da casa. Bazar litterário: de educação e de recreação. Rio de Janeiro: Typographia de São Vicente de Paula, 1878. (1. ed. 1878-1879).

DUNLOP, Charles Julius. Chronicas: fatos, gente e coisas da nossa história. Rio de Janeiro: Editora Americana, 1973.

EDMUNDO, Luís. O Rio de Janeiro no tempo dos vice-reis: 1763-1808. Niterói: Imprensa Oficial, 2007. Janeiro, 2009.

O Rio de Janeiro do meu tempo. Niterói: Imprensa Oficial do Estado do Rio de

FERNANDES, Rogério. Os caminhos do ABC. Sociedade portuguesa e ensino das primeiras letras. Porto: Porto Editora, 1994.

FRANÇA, Jean Marcel Carvalho (Org.). Visões do Rio de Janeiro colonial: antologia de textos, 1531-1800. Rio de Janeiro: José Olympio Editora, 1999.

Olympio, 2008.

Mulheres viajantes no Brasil (1764-1820): antologia de textos. Rio de Janeiro: José 2013.

. Viajantes estrangeiros no Rio de Janeiro joanino. Rio de Janeiro: José Olympio,

FREYRE, Gilberto. Casa-grande e senzala. 32. ed. Rio de Janeiro: Record, 1997.

. Sobrados e mucambos. 14. ed. São Paulo: Global, 2003.

Global, 2010.

O escravo nos anúncios de jornais brasileiros do século XIX. 4. ed. São Paulo:

GERSON, Brasil. História das ruas do Rio. 6. ed. Rio de Janeiro: Bem-te-vi, 2013. 
JINZENJI, Mônica Yumi. Cultura impressa e educação da mulher no século XIX. Belo Horizonte: Editora UFMG, 2010.

LEITE, Míriam Moreira. A condição feminina no Rio de Janeiro século XIX. São Paulo: HUCITEC, 1984.

MALTA, Marize. $O$ olhar decorativo: ambientes domésticos em fins do século XIX no Rio de Janeiro. Rio de Janeiro: Mauad X Faperj, 2011.

MONTEIRO, Maria Conceição. Sombra errante: a preceptora na narrativa inglesa do século XIX. Niterói: EdUFF, 2000.

MOURA, Ana Maria da Silva. Cocheiros e carroceiros. Homens livres no Rio de senhores e escravos. São Paulo: HUCITEC, 1988.

NASH, Mary. As mulheres no mundo. Madrid: Editorial Alianza, 2004.

OLIVEIRA, Cláudia de. Mulheres de estampa: o folhetim e a representação do feminino no Segundo Reinado. In: KNAUSS, Paulo; MALTA, Marize; OLIVEIRA, Cláudia de; VELLOSO, Mônica Pimenta. Revistas ilustradas: modos de ler e ver no Segundo Reinado. Rio de Janeiro: Mauad X Faperj, 2011.

PAIVA, Eduardo França. Imagens, ritmos e formas nas sociedades americanas vistas por estrangeiros. In: CURY, Claudia Engler; ROCHA, Solange Pereira da (Org.). Culturas e sociabilidades no oitocentos: possibilidades de pesquisa. João Pessoa: Editora UFPB, 2011.

PINHO, Wanderley José. Salões e damas do Segundo Reinado. 5. ed. São Paulo: GRD, 2004.

POLLOCK, Linda. Educação e ensino cultural dos ingleses em casa de 1550 a 1800. Revista Educação \& Realidade, Porto Alegre, v. 35, n. 3, p. 17-35, set./dez. 2010.

QUINTANEIRO, Tania. Retratos de mulher: o cotidiano feminino no Brasil sob o olhar de viageiros do século XIX. Petrópolis: Vozes, 1996.

RENAULT, Delso. O dia-a-dia no Rio de Janeiro segundo os jornais 1870-1889. Rio de Janeiro: Civilização Brasileira, 1982.

SENNA, Ernesto. O velho comércio do Rio de Janeiro. 2. ed. Rio de Janeiro: G. Ermakoff Casa Editorial, 2006.

SOUZA, Gilda de Mello. O espírito das roupas: a moda no século dezenove. São Paulo: Companhia das Letras, 1987.

VARIEDADES. O album semanal. Chronologico, litterario, crítico e de moda, Rio de Janeiro, p. 1, 21 dez. 1851.

VASCONCELOS, Maria Celi Chaves. A casa e seus mestres: a educação no Brasil de oitocentos. Rio de Janeiro: Gryphus, 2005.

. Vozes femininas do oitocentos: o papel das preceptoras nas casas brasileiras. In: LÔBO, Yolanda; FARIA, Lia (Org.). Vozes femininas do Império e da República. Rio de Janeiro: Quartet/Faperj, 2008.

Mulheres preceptoras no Brasil oitocentista: gênero, sistema social e educação feminina. In: FRANCO, Sebastião Pimentel; PALHARES SÁ, Nicanor (Org.). Gênero, etnia, e movimentos sociais na história da educação. Vitória: Edufes, 2011.

. Domestic education in nineteenth century Brazil: Aspects of european Influence on the performance of tutors and private teachers. HSE - Social and Education History, v. 2, n. 1, p. 1-22, feb. 2013. 
. A escrita cotidiana no diário de lembranças da Viscondessa de Arcozelo: fragmentos (auto) biográficos de um egodocumento. In: VASCONCELOS, Maria Celi Chaves; CORDEIRO, Verbena Maria Rocha; VICENTINI, Paula Perin (Org.). (Auto) biografia, literatura e história. Curitiba: CRV, 2014.

Uma mulher educada no oitocentos: a escrita feminina no diário da Viscondessa de Arcozelo. Revista Educação em Questão, Natal, v. 53, n. 39, p. 104-131, set./dez. 2015.

VERONA, Elisa Maria. Da feminilidade oitocentista. São Paulo: Editora Unesp, 2013.

VISCONDESSA DO ARCOZELO. Diário de lembranças. Rio de Janeiro: Publicado por Antônio José Gomes Brandão, 1887. 